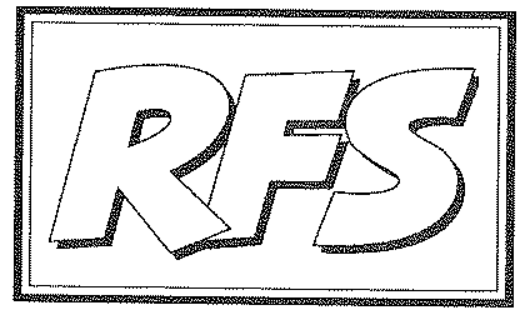

Revista de Fomento Social, 51 (1996), 297-318

\title{
El reto de la pobreza
}

\section{Actualidad del tema}

El año 1996 fue declarado por la Asamblea General de las Naciones Unidas Año Internacional para la erradicación de la pobreza; algo tan urgente como utópico: iparece poco tiempo un año para erradicar la pobreza en el mundo! La Asamblea General de las Naciones Unidas lanzaba el siguiente mensaje al mundo:

«Invita a todos los Estados, las organizaciones del sistema de las Naciones Unidas y las organizaciones intergubernamentales y nacionales interesadas, incluidas las organizaciones no gubernamentales, a que colaboren todo lo posible en los preparativos y la observancia del Año.

Invita a todos los paises a que pongan en marcha estrategias $y$ programas nacionales para erradicar la pobreza que, entre otras cosas, incorporen una participación equitativa del hombre y de la 
mujer, tengan en cuenta particularidades culturales, religiosas y sociales, y entrañen una participación más efectiva de las comunidades beneficiarias, asi como de los grupos más vulnerables, en la concepción, la ejecución, las actividades complementarias y la evaluación de proyectos concretos...».

Esta ocasión nos da pie a sumarnos a esta corriente de preocupaciones. Se trata también, en iltimo término, de cumplir los compromisos de la declaración final de la Cumbre Mundial sobre Desarrollo Social de Copenhague:

«Nos reunimos aqui para contraer el compromiso, junto a nuestros gobiernos y naciones, de promover el desarrollo social en todo el mundo para que todos los hombres y mujeres, particularmente los que viven en la pobreza, puedan ejercer sus derechos, utilizar los recursos y compartir las responsabilidades que les permitan llevar vidas satisfactorias y contribuir al bienestar de sus familias, de sus comunidades y de la humanidad...» (1).

Pero además, cuando este número de la revista llegue a nuestros lectores habrá tenido lugar el Congreso Nacional sobre "Los desafios de la pobreza a la acción evangelizadora de la Iglesia). Se trata de una iniciativa aprobada por la Asamblea Plenaria de la Conferencia Episcopal Española en 1993 (2) con el objeto de animar y renovar la acción pastoral de la Iglesia frente a la pobreza. El congreso ha sido preparado concienzudamente, partiendo de excelentes materiales de trabajo (3) elaborados con la participación especial de la Comisión Episcopal de Pastoral Social.

(1) NaCIONES UNDAS (ONU) (1995). Declaración y programa de acción de la Cumbre mundial sobre desarrollo social. Copenhague, marzo. Remitimos a nuestros lectores a nuestro editorial del n० 199: «De Cumbre en Cumbre».

(2) En la LX asamblea de 15-20 de noviembre de 1993 los obispos españoles publicaron un documento titulado «La caridad en la vida de la Iglesia» que contenía una serie de propuestas para la acción pastoral.

(3) Congreso Nacional. Los desafios de la pobreza a la acción evangelizadora de la Iglesia. Ed. Comisión Episcopal de la Pastoral Social. 
Cáritas española, CONFER, FERS, Asociaciones Vicencianas y la Comisión nacional Mixta de Pastoral de la Caridad. Esos materiales han sido objeto de estudio, debate y aplicación en muchos ámbitos de la Iglesia española.

El título de nuestro artículo editorial se inspira precisamente en el de los documentos básicos de preparación de dicho congreso: «La pobreza, un reto a la sociedad» y «La pobreza, un reto a la evangelización». Nuestro comentario no pretende, ni mucho menos, ser un estudio más sobre la pobreza: los hay, y muy buenos. Sólo deseamos hacernos eco de estos recordatorios, y contribuir con estas sencillas reflexiones a los esfuerzos que acá y allá se hacen para concienciarnos a todos en la lucha contra la pobreza.

Por desgracia, el tema de la pobreza está de plena actualidad por razones mucho menos coyunturales que las dos aludidas al comienzo de muestro comentario editorial. La pobreza es un reto hoy para todos por la sencilla razón de que el número de los pobres es muy elevado y que la gravedad de los problemas que les afectan es abrumadora.

\section{Los pobres del mundo son muchos}

En un texto evangélico muy comentado, cuando la mujer arrepentida lavó con perfume caro los pies de Jesús, ante la crítica de despilfarro de sus amigos, el maestro comentó: "Dejadla en paz... A los pobres los tenéis siempre con vosotros y podréis hacerles bien cuando queráis» (4). Prescindiendo de otras consideraciones, bien puede decirse que esa profecía se cumple de manera ejemplar, excesiva, en nuestros dias. A escala mundial, al menos en términos relativos, nunca hubo tantos pobres como en nuestro tiempo. Es cierto que ha habido épocas en siglos pasados, en que, incluso en las zonas más «adelantadas» del planeta, la mayor parte de la población vivia en condiciones objetivas de penuria material; más aún, las condiciones materiales de vida de los que se consideraban ricos $y$ poderosos eran, en términos absolutos, muy sobrias. Seguramente tendrian mucho poder, y en términos relativos serian mucho más ricos que

(4) Evangelio de Marcos, capítulo 14, versículo 7. 
sus súbditos, pero en cuanto a comodidades y recursos materiales de todo tipo, los Reyes Católicos o el mismo Felipe II, vivian por debajo del nivel de vida de un ciudadano medio europeo actual. Sin embargo, la desigualdad en niveles de consumo material y de vida de aquellas épocas era muy inferior a la actual; $y$, en consecuencia, los niveles de lo que podriamos llamar «pobreza subjetiva» o relativa, eran inferiores a los actuales y desde luego ésta afectaba a una cantidad incomparablemente menor de población.

La pobreza admite muchas definiciones, y su consideración puede ser absoluta u objetiva (pobre es el que no llega a los niveles elementales de ingreso para satisfacer las necesidades básicas) o relativa o subjetiva (pobre es, por ejemplo, el que se siente tal, o el que está por debajo de la mitad de la media de su país, región etc.). Según las estadísticas del Banco Mundial (BM), en 1990 se sitúan por debajo del umbral de pobreza severa, es decir, son extremadamente pobres, más de 600 millones de habitantes, mientras que más de 1.100 millones de habitantes de la tierra se encuentran por debajo del umbral de la pobreza, establecido en $420 \$$ anuales.

Frente a un frecuente error homogeneizador, al contemplar el mapa mundial de la pobreza por grandes continentes y regiones, se observa que las diferencias en los niveles de renta per cápita, incluso entre los pobres, son considerables. Según los datos del Banco Mundial, para el final del presente decenio, alrededor de la mitad de los pobres del mundo vivirá en Asia y una cuarta parte en Africa al sur del Sahara. Africa es con mucho el continente peor situado, seguido por Asia del Sur y América Latina. Por hablar de paises concretos, por ejemplo, de los 10 paises peor situados en esta clasificación del Banco Mundial en su publicación de 1995, nueve pertenecen al Africa subsahariana.

Pero la medición de la pobreza puede hoy hacerse con indicadores bastante menos groseros que el de la renta per cápita (aunque se utilicen cifras con equivalente poder adquisitivo, o paridad de poder de compra) que acabamos de citar. Nuestros lectores seguramente conocen los excelentes y muy citados "Informes sobre Desarrollo Humano" publicados por el Programa de Naciones Unidas para el Desarrollo; en estos informes anuales el citado organismo especializado de la $O N U$ realiza un ranking de todos los paises del mundo utilizando un indicador que incluye, además 
del nivel de renta per cápita, indicadores de salud y esperanza de vida y nivel de educación. Es decir, se trata de un indicador que intenta cuantificar un criterio de desarrollo no meramente económico, y que tiene en cuenta variables importantes de calidad de vida.

También según este indicador de los 10 paises con menor nivel de desarrollo humano, nueve son africanos: Angola, Burundi, Mozambique, Etiopia, Burkina Faso, Mali, Somalia, Sierra Leona, y Niger; uno es asiático: Afganistán. Se observa que, aunque no haya coincidencia total con los datos del BM, si que se repite la concentración de la pobreza extrema o del bajo desarrollo humano en el continente africano.

\section{Pero, aquí también hay pobres...}

Cuando se habla de los pobres, utilizando un enfoque global, planetario, e insistiendo además en la necesidad de la ayuda solidaria hacia los paises empobrecidos, surge con frecuencia una reacción legitima y lógica: aqui también hay pobres. Efectivamente, según los criterios estadísticos de la Unión europea, que utilizan un indicador relativo de pobreza, se consideran pobres los habitantes de un pais cuya renta per cápita sea inferior a la mitad de la renta per cápita media. En España, según los resultados del V Informe sociológico sobre la situación social de España - FOESSA '93, una quinta parte de la población estaría por debajo del umbral de la pobreza, es decir alrededor de 7.950.000 personas. En pobreza severa -es decir, por debajo de la mitad del umbral de la pobreza-se encontraría alrededor de un millón y medio de personas.

Por tanto, es cierto que «aqui también hay pobres». Es cierto, también, que este concepto de pobreza hace referencia a una serie de necesidades que no todas son vitales para la subsistencia: uno es pobre comparado con su vecino o con la población de su entorno, y sufre por no poder alcanzar sus niveles de vida. Naturalmente, los umbrales serian más altos y elevarian el contingente de pobres si la comparación se hiciera con la renta per cápita media de la Europa comunitaria.

Ciertamente, no hay punto de comparación entre la situación de penuria de un pobre español (no nos referimos ahora al colectivo más reducido de los mendigos y marginados extremos) y la de un habitante pobre de los 
paises antes mencionados. En nuestros paises desarrollados, cuando nos referimos a la población pobre (por ejemplo, desempleados del medio rural y sus familias) no ignoramos que hablamos de personas que tienen la inmensa mayoria de las veces algún subsidio, y que poseen una vivienda digna, agua corriente y luz, alcantarillado, servicios de salud y educativos de nivel relativamente satisfactorio, transportes públicos a su alcance etc... Todos ellos bienes materiales y servicios que no están ni de lejos al alcance de la inmensa mayoría de los pobres de los paises empobrecidos.

\section{Una primera aproximación a las explicaciones de la pobreza}

Comencemos enumerando algunas de las explicaciones de la pobreza en la actualidad, sin entrar en grandes análisis ni siquiera pretender jerarquizarlas por orden de influencia, ya que su incidencia varia mucho según las regiones.

A) El paro y la falta de horizontes laborales

Aunque el desempleo no es un fenómeno exclusivo de esta época, lo que lo diferencia del pasado es que antes los pobres eran los trabajadores de determinados niveles laborales, mientras que hoy los pobres son, principalmente, los que no trabajan. En otras épocas, los ricos y las clases acomodadas, con frecuencia, no trabajaban, por el contrario, en la actualidad la riqueza coincide con algunos trabajos de alto nivel.

B) El consumo de drogas

Existe una correlación entre las drogas y la pobreza. Los consumidores de droga caen con frecuencia en la miseria, la mendicidad y el delito; pero también los ambientes más pobres y marginados pueden ser, por su falta de horizontes de todo tipo, el semillero de drogadictos; el SIDA y otras enfermedades, frecuentes entre los consumidores de drogas, refuerzan la marginación y la pobreza.

C) Las guerras y los conflictos bélicos

Los enfrentamientos entre paises y sobre todo entre diferentes etnias y grupos dentro de un mismo país se producen precisamente en las zonas más 
pobres y atrasadas, provocando desplazamientos de poblaciones enteras que quedan por debajo de los niveles de pobreza, determinando graves situaciones de hambre e incluso la muerte de los elementos más débiles de la población.

D) Catástrofes naturales

Terremotos, inundaciones, sequias, son fenómenos naturales que, cuando afectan a los paises en desarrollo, dan lugar a situaciones de emergencia que provocan el empobrecimiento y el hambre de grandes contingentes de población.

E) La marginación social

Existen ciertos grupos sociales marginados -inmigrantes, gitanos $y$, en cierto modo, los ancianos- que presentan niveles de pobreza más intensos que los grupos que pudiéramos llamar normales. La creación de guetos para algunos de estos grupos contribuye a la generalización de las condiciones de pobreza y a los sentimientos de frustración.

Cabría todavia citar otras explicaciones de la pobreza: la falta de cultura de amplias capas de la población, la corrupción y la acumulación de riqueza de las élites de los paises atrasados, la autoexclusión de ciertos grupos étnicos etc. Son también razones que explican la pobreza en muchos casos.

\section{La causa última de la pobreza}

La enumeración que precede permite reconocer que la pobreza afecta a grupos especialmente vulnerables. ¿O es que las catástrofes naturales, que escapan en principio a la voluntad humana, tienen los mismos efectos en los distintos paises? No es lo mismo un tornado en Miami que en Nicaragua; ni producen los mismos efectos las lluvias torrenciales en el centro de Caracas que en los ranchos de la periferia... Luego la pobreza afecta con mayor dureza a los colectivos más indefensos ante ella, a quienes están en condiciones de mayor vulnerabilidad.

Cabe todavía preguntar si existe una causa última de la pobreza. Sin caer 
en la demagogia, se puede afirmar que -al margen de casos particulares- la pobreza existe porque el sistema socio-económico crea, de forma espontánea, la desigualdad. Sin negar lo positivo de una sociedad basada en la libertad como valor supremo, es preciso reconocer también que el ejercicio de la libertad conduce inevitablemente a la desigualdad, porque es casi imposible que todos tengan, y mantengan, el mismo grado de libertad. Porque la libertad se posee, no de modo absoluto (se tiene o no se tiene), sino en forma relativa: disponemos de diferentes cotas de libertad, unos tenemos más y otros menos. Y si la libertad tiende a redistribuirse desigualmente, las posibilidades de cada uno para valerse por si mismo, para defenderse y atender a sus necesidades, tampoco están igualitariamente repartidas. El paro -por hablar de un fenómeno que nos es tan familiar-es un buen ejemplo de lo que decimos: sin trabajo es dificil acceder a los recursos de la sociedad, pero la libertad de trabajar no está al alcance de todos.

Ya dijimos que la pobreza es un fenómeno relativo. La pobreza en nuestro mundo desarrollado tiene caracteristicas muy distintas a la de los paises atrasados, aunque no menos dramáticas. Pero, tanto en un sitio como en el otro, tiene mucho que ver con la lógica del sistema capitalista. $Y$ en esta lógica hay que incluir no sólo los mecanismos económicos, sino también el conjunto de valores dominantes. Porque la sociedad del consumismo y las pautas de conducta impuestas por la publicidad y la propaganda -factores consustanciales a la economia de finales del siglo $X X$ - agravan los sentimientos de frustración de las personas más pobres, dando un carácter más trágico a la pobreza actual.

Más aún, en este sistema que genera desigualdad no hay voluntad para atenuar estas tendencias espontáneas de la dinámica social. No se trata ahora de volver a una sociedad tutelada y sin libertades, sino de contrarrestar los efectos socialmente negativos de esa libertad, que es beneficiosa por tantos otros conceptos. En el fondo, estamos aqui nuevamente en el debate sobre el mercado. Y no es el momento de entrar en él con detalle. Pero si conviene insistir, también desde esta perspectiva, en la importancia del mismo (5).

(5) Véase nuestro editorial «Crisis y futuro del Estado de bienestar». Revista de Fomento Social, $n^{\circ} 198$, abril-junio 1995 , pp. 149-169. 


\section{Los círculos viciosos de la pobreza}

Se suele hacer la consideración de que la pobreza de los paises empobrecidos va acompañada de una desigual distribución de la renta. Pero no es raro olvidar que una mala distribución de la renta es, a su vez, causa de la propia pobreza.

Como destaca Michael Todaro, un clásico del estudio del desarrollo económico del Tercer Mundo (6), pobreza y mala distribución de la renta suelen ir indisolublemente unidas. Los datos empíricos y unos sencillos análisis macroeconómicos demuestran que, en un pais pobre considerado en su conjunto, una distribución de la renta muy desigual significa que los pocos individuos ricos de ese pais (que detectan la mayor parte de la renta) dictan de hecho las pautas de la producción, pues sus preferencias y su demanda tienen más fuerza en el mercado de bienes que las de los individuos pobres. Así, pues, para un nivel bajo dado de PNB y renta per cápita, cuanto más desigual sea la distribución de la renta, más elevada será la proporción de la demanda agregada y de la producción que estará influida por las preferencias de consumo de los ricos. Su preponderante poder de compra sesga la producción y las importaciones hacia los productos industriales de lujo, frecuentemente de importación, aun cuando la mayor parte de la población se encuentre en un nivel cercano al de subsistencia.

En realidad lo que se está poniendo aqui de relieve es algo que la teoria económica a veces disimula cuando habla de la soberanía del consumidor: que el consumidor es soberano, si, pero con tal que tenga capacidad de compra, porque en el mercado no «mandan» las necesidades de la población, sino los recursos económicos que acompañan a estas necesidades (es decir, la demanda solvente, y sólo ella). Si la renta estuviese distribuida de forma más equitativa, las pautas de la demanda estarían más encaminadas hacia la producción de alimentos y otros bienes necesarios. Esto ayudaría a eliminar la pobreza rural y elevaría los niveles de vida de segmentos más amplios de la población.

(6) M.P. Todaro (1988), El desarrollo económico del Tercer Mundo. Alianza Universidad

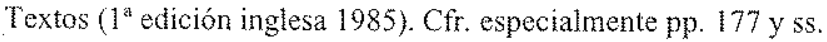


Algunos corolarios de las anteriores consideraciones serian los siguientes: una renta per cápita nacional elevada no garantiza por si misma que el número de personas absolutamente pobres sea bajo; el crecimiento económico por si solo, si no va acompañado por una real mejora en la distribución de la renta, no es solución al problema de la pobreza; las politicas directas tendentes a mejorar la distribución de la renta son en sí mismas una de las principales armas de lucha contra la pobreza. Y téngase en cuenta que todas estas consideraciones no se hacen en el vacio: segín la famosa revista Forbes, jmenos de 500 multimillonarios, los más ricos del mundo, tienen unos ingresos equivalentes al $45 \%$ de la población mundial, es decir, de unos 2.400 millones de personas!

Pero el único círculo vicioso de la pobreza no es el que liga a ésta con la distribución de la renta. Hay otro más global porque desborda el enfoque preferentemente económico en que se mueve éste último. Nos referimos al circulo vicioso de pobreza y marginación. Ser pobre no es sólo carecer de medios económicos: es, además, vivir al margen de la sociedad, excluido de ella. Esta exclusión se manifiesta en el hecho de no tener acceso a los recursos de que la sociedad dispone, y que, en muestro mundo desarrollado, son abundantes. No es que no se tiene derecho a llegar a ellos: más dramáticamente, es que se carece de las habilidades para acceder. Es una exclusión de hecho, más que de derecho. Por decirlo mejor, con palabras de poeta:

\section{Los nadies}

los hijos de nadie, los dueños de nada.

Los nadies:

los ningunos, los ninguneados,

corriendo las liebres, muriendo la vida, jodidos, rejodidos:

Que no son, aunque sean,

Que no hablan idiomas, sino dialectos.

Que no profesan religiones, sino supersticiones.

Que no hacen arte, sino artesania.

Que no practican cultura, sino folklore.

Que no son seres humanos, sino recursos humanos. 
Que no tienen cara, sino brazos.

Que no tienen nombre, sino número.

Que no figuran en la historia universal,

sino en las páginas rojas de la prensa local.

Los nadies, que cuestan menos que la bala que los mata.

Eduardo Galeano (7)

Este circulo vicioso es tan riguroso que la pobreza termina identificándose hoy, en no pocos estudios sociales, con la marginación o con la exclusión. Pero esta identificación, que revela el verdadero alcance de la pobreza en nuestro mundo de opulencia, no debe ocultar el carácter dinámico de este fenómeno: si la pobreza conduce a la marginación, la marginación es el caldo de cultivo más adecuado para que la pobreza se perpetúe.

\section{Las dimensiones culturales de la pobreza}

La vinculación estrecha de la pobreza con la marginación permite hablar de una verdadera cultura de la pobreza, entendiendo por tal una cierta forma de vivir y de situarse ante la sociedad, incluso un conjunto de valores compartidos por los que se encuentran en esa situación. Esto introduce una nueva dificultad en la lucha contra ella, ya que esa cultura ofrece no pocas resistencias para ser eliminada.

Pero la dimensión cultural de la pobreza tiene otros aspectos que fácilmente se confunden entre si. Ante todo, hay que hablar de una cultura moderna, que podriamos caracterizar como la cultura dominante. Ella es la que ha hecho posible, en gran parte, el desarrollo económico contemporáneo, aunque sea al precio de grandes desigualdades e injusticias. Es evidente que no todo lo occidental es malo, ni todos los avances técnicos son negativos; pero la tendencia a canonizar e imponer (con un cierto neoimperialismo cultural) cuanto en el mercado tiene un valor y cuanto en determinados ámbitos culturales es apreciado es una parte esencial del problema del subdesarrollo. El diálogo con la cultura moderna tendrá que

(7) E. Galeano (1989), «Los nadies》. El libro de los abrazos. Ed. Alianza, Madrid.

\section{EDITORIAL}


ser critico, ante el hecho innegable de que, en el banquete de la humanidad, la mayoría se encuentra excluida. Esta presencia en el mundo de la llamada «modernidad» es una tarea ingente y, si cabe, más dificil de llevar a cabo que la lucha por la defensa directa de los intereses de los pobres y los excluidos.

Es más, el cambio social no puede ya pensarse sólo en términos de transformación de las estructuras sociopolíticas y económicas, puesto que éstas tienen sus raices en valores y actitudes socioculturales. Es preciso, también trabajar en la transformación de los valores culturales que en muchos lugares sostienen un orden social represivo e injusto. Frente a planteamientos excesivamente unidimensionales de indole politica o económica, hoy podemos reconocer que los fracasos de algunas revoluciones -o la misma falta de resultados de los modelos de socialismo real- tienen mucho que ver (entre otros factores) con formas de pensar $y$ de vivir que han interiorizado la dependencia, la dominación y la falta de espiritu de lucha y de capacidad de innovación y de creatividad.

Pero esta cultura dominante coexiste con otras culturas particulares, que el modelo de desarrollo impuesto desde Occidente amenaza con arrasar. ¿Es posible un desarrollo que respete esas culturas autóctonas, patrimonio inestimable de otros tantos pueblos? Indudablemente debe aumentar la conciencia y el respeto de la diversidad cultural: «la emergencia de lo diferente». Una parte importante del desarrollo de los pueblos es el crecimiento de su autoestima; considerar los propios valores culturales, la lengua, el folclore, las costumbres o el arte, como auténticas riquezas, y no "venderse» a la invasión inmisericorde de las pautas culturales del paradigma dominante es una componente ineludible del auténtico desarrollo.

Pero tampoco pueden ignorarse las limitaciones y deficiencias de estas culturas. Y no estará de más un diálogo también crítico con ellas. Porque muchas de las injusticias que marcan el mundo de hoy no son sólo de orden socio-económico o socio-politico, sino que también y sobre todo de orden socio-cultural y socio-religioso. Cada vez vemos con más claridad que muchos problemas contemporáneos de extrema gravedad sólo pueden entenderse desde rasgos más que problemáticos de esas culturas: piénsese en: la crisis yugoslava, en el fundamentalismo islámico, en los conflictos 
raciales en Africa o en el contencioso árabe-israeli. Todos ellos tienen sin duda importantes componentes económicas y políticas, pero nunca serán adecuadamente resueltos si no se atacan sus profundas raices culturales. Por tanto, siempre habrá que dialogar criticamente con aspectos inaceptables de esas culturas, que la cultura dominante tiende a eliminar. No todos los valores culturales de los pobres son compatibles con su propio desarrollo, aunque eso no signifique que tengan que copiar miméticamente a los paises llamados avanzados.

\section{Actitudes positivas ante la pobreza: cuatro etapas}

No entramos siquiera a considerar aqui la actitud que consiste en la indiferencia o la insolidaridad, o simplemente en «mirar para otro lado» ante la dimensión y la dificultad del problema.. Para ello no merece la pena siquiera escribir un articulo editorial... Simplificando en una tipología que ayude a reflexionar y a ubicarse a cada uno, y siguiendo a Albert Nolan (8), podemos hablar de 4 etapas en la preocupación por la pobreza y por los pobres y en el deseo de ayudar a paliar la pobreza:

* La primera etapa se caracteriza por la «compasión»

Todos hemos experimentado una emoción personal al ver o al oir hablar del sufrimiento de los pobres. Es el punto de partida. Cuanto más nos exponemos al sufrimiento de los pobres, más profunda y durable se hace en nosotros la compasión. Nada puede sustituir al contacto directo con el sufrimiento y el hambre, al ver a la gente expuesta al frio y la lluvia tras el derribo de sus casas, sentir la sensación intolerable de un barrio de chabolas, ver los vientres de los niños que sufren desnutrición.

Esta compasión creciente conduce a una acción de dos tipos. El primero consiste en eso que normalmente se llama «acción asistencial»: recogida de alimentos, mantas, vestidos... El segundo tipo consiste en simplificar nuestro estilo de vida, renunciando a todo lo superfluo y dando a los pobres parte de muestro dinero.

(8) A. Nolan (1991), Opción por los pobres y crecimiento espiritual, en: J.M. ViGL. (Ed), La opción por los pobres, Sal Terrae, Santander, pp. 89-98. 
* La segunda etapa consiste en el descubrimiento del problema estructural de la pobreza

Descubrimos que la pobreza no es un simple asunto de mala suerte, de desaprovechamiento de oportunidades, fruto de la pereza o la ignorancia o simplemente de la falta de desarrollo o de cultura. Algo inevitable. La pobreza es el resultado directo de estructuras politicas y económicas. No es un accidente, sino una consecuencia. Está producida por determinados sistemas y determinadas politicas. La pobreza entonces es una cuestión de justicia e injusticia. Los pobres sufren y son oprimidos por una terrible injusticia. La avidez de los ricos es la causa del sufrimiento de los pobres.

Ante este problema estructural surge la indignación y la cólera, contra todo y todos los que producen pobreza y sufrimiento. En este etapa debe cambiar nuestra actividad. Conocer el mal estructural nos debe mover a cambiar la sociedad. La acción asistencial mira más a los sintomas que a las causas. Pero ahora se trata más de prevenir que de curar. Queremos cambiar las estructuras y no sólo ayudar a la gente que sufre las consecuencias del sistema injusto.

Esta nueva conciencia puede dar lugar a una extraordinaria actividad, aunque algunos experimentan una paralización. ¿Qué hacer contra un sistema? ¿No es una guerra inútil? iSiempre habrá pobres! En lo profundo de la persona se produce una lucha interna.

* La tercera etapa viene marcada por el convencimiento de que los pobres deben salvarse ellos mismos

Habrá que moverse y ayudarles, pero tendemos siempre a tratar a los pobres como personas incapaces. Y nos produce una especie de «shock» cuando descubrimos que ellos saben mejor que nosotros qué hacer y cómo hacerlo. Y yo tengo que aprenderlo, tengo que salvarme gracias a su sabiduría. Yo necesito algo que sólo ellos pueden darme.

La tentación en esta tercera etapa es el romanticismo. Es tentador hablar de la maravilla de la clase obrera o de los pobres. Tendemos a ponerlos en un pedestal. Si alguien pobre dice algo, debe ser infaliblemente cierto, si alguien viene del Tercer Mundo, hay que recibirlo como lo mejor. Si los pobres hacen algo, es lo que hay que hacer... Ese romanticismo nos 
puede llevar a una crisis de desilusión, porque nos pueden defraudar y no realizar esa imagen heroica que nos habiamos formado de ellos. Algo falla, porque hemos entendido mal. No hemos entendido bien el problema estructural. Los pobres, en si mismos, no son diferentes de cualquier otro ser humano: tienen sus problemas y defectos.

* La cuarta etapa podría definirse como la de solidaridad real con los pobres oprimidos

Esta etapa comienza con la desilusión y decepción que experimentamos al descubrir que los pobres no son lo que románticamente pensábamos de ellos. Son muchas veces egoistas, despilfarran su dinero, son irresponsables, tienen aspiraciones de ricos, se dejan influir por la propaganda, no siempre están en la lucha social y politica...

A pesar de todo se van a salvar por si mismos, debemos aprender de ellos, sólo ellos efectuarán el cambio social. Es cuestión de pasar del romanticismo ingenuo al realismo honrado y auténtico, y asi entrar en la cuarta etapa de solidaridad real.

Esta solidaridad comienza cuando desaparece la. cuestión del «nosotros» y el «ellos», cuando cerramos la fosa profunda que nos separa $y$ descubrimos que todos tenemos defectos e inconsecuencias, que no vivimos como pensamos (9). Además, cada uno tiene sus cualidades, sus responsabilidades. Somos conscientes de nuestras diferencias reales. Pero solidaridad significa que todos hemos elegido estar del mismo lado, contra la opresión. Podemos trabajar y luchar juntos contra muestro enemigo comin, las politicas y sistemas injustos, sin considerarnos nunca unos a otros inferiores o superiores, respetándonos mutuamente.

Estos cuatro niveles descritos no son rigidos ni matemáticos. Se podrán entremezclar y exigirán vivir en proceso continuo. Pensamos que su descripción es útil para ayudar a ubicarnos existencialmente en nuestra lucha individual o colectiva contra la pobreza.

(9) Aqui viene bien recordar el verso de Loidi: Nadie libera a nadie, pero nadie se libera solo, que los hombres y mujeres nos salvamos todos juntos. 


\section{Algunas iniciativas para la erradicación de la pobreza}

Hay que reconocer que son muchas las iniciativas que hoy se acometen de lucha contra la pobreza, y que son muchos los agentes involucrados en ella. Presentamos a continuación algunas de estas iniciativas, que encontramos en nuestro entorno, porque las consideramos de especial interés.

\section{A) Las ayudas de emergencia}

Comenzamos por lo más coyuntural. Los envios de alimentos y otros bienes de primera necesidad, asi como las aportaciones para la reconstrucción de regiones o países que han sufrido catástrofes o guerras, han cumplido en general su objetivo de salir al paso de situaciones de extrema urgencia. Son expresión de una cierta solidaridad mundial, marcada por el impacto de esas situaciones, en las que participan, no sólo los gobiernos, sino muchas veces instituciones de todo tipo y personas particulares. Desgraciadamente, sin embargo, no se han librado de algunos abusos y corrupciones, en los paises donantes $y$, con más frecuencia, en los receptores.

\section{B) La ayuda al desarrollo}

Se trata de una contribución más sistemática y básicamente protagonizada, o al menos coordinada por los gobiernos. En sus comienzos tuvieron elevadas dosis de buena voluntad; con el paso del tiempo han evolucionado, dando un mayor peso en su concesión a los criterios politicos y, lo que es peor, condicionando las ayudas a los intereses de las industrias exportadoras. La ayuda multilateral que, con frecuencia, se ha valorado como una solución a estos defectos, ha ido perdiendo importancia en la época más reciente.

C) El reparto del trabajo

Siendo el paro una de las causas principales de la pobreza, es evidente que todo lo que puede incrementar el empleo seria positivo para la erradicación de la pobreza. Una de las propuestas en este sentido es el reparto del trabajo, es decir, la reducción de las jornadas laborales, propuesta, sin embargo, que rechazan las empresas y la mayor parte de los gobiernos. 
D) La educación primaria y la medicina preventiva

Si la pobreza tiene mucho de marginación y de vulnerabilidad en determinados colectivos sociales, la lucha contra ella sólo será efectiva si ataca a las causas de esa situación de inferioridad. Por eso el desarrollo humano básico es esencial para conseguir, como se ha dicho más arriba, no salvar a los pobres, sino que los pobres se salven a si mismos.

E) La economía informal

De hecho está siendo una salida importante para grupos en extrema pobreza en muchos países del tercer mundo. No hay que pensar sólo en actividades ilegales, que es el sentido que damos generalmente en los paises avanzados a la expresión «economia informal», sino a todas aquellas actividades surgidas del pueblo más pobre y marginado que les permiten, al menos en un primer momento, obtener unos recursos minimos para sobrevivir. La importancia de estas iniciativas radica en que son un punto de partida para la organización de pequeñas comunidades locales, que toman conciencia de que sus posibilidades son mayores de lo que pensaban: por tanto, tales iniciativas están en la linea de ese "salvarse a si mismos» ya mencionado.

Los agentes que intervienen en todas estas iniciativas son variados. Acabamos de hablar de los propios interesados, que son los más decisivos. Hemos mencionado también a los gobiernos. Permitásenos mencionar todavia a otros tres, por la importancia que adquieren en estos momentos.

Ante todo hay que citar a las organizaciones no gubernamentales $(O N G)$. Las $O N G$, muy diversas en objetivos y métodos, tienen un papel importante en el desarrollo de áreas atrasadas, y en menor medida, de los grupos de pobreza de los paises adelantados. Entre sus campos prioritarios de actuación hay que mencionar los de la educación y la medicina preventiva, pero también están contribuyendo decisivamente a potenciar diferentes iniciativas de economia informal. Su actuación, sin embargo, tropieza con no pocos problemas, de los que cabe destacar dos: a) la limitación de recursos que reducen la posibilidad de resolver los ingentes problemas que tratan de atender; y b) el sometimiento a criterios politicos en aquellos casos, bastante abundantes, en que reciben la mayor parte de 
su financiación de los organismos públicos.

Es también destacable el papel de las organizaciones religiosas. Además de su labor religiosa en sentido estricto, estas organizaciones dedican gran parte de sus medios a la asistencia a los pobres, bien a través de actividades caritativas, bien mediante actuaciones semejantes a las de las ONG. La orientación en cierto modo paternalista de estas entidades se va reorientando en muchos casos hacia la ayuda al desarrollo e incluso hacia la economía alternativa.

Por último, aunque en un nivel diferente, hay que mencionar a los organismos internacionales. Junto con las instituciones de Bretton Woods (Fondo Monetario Internacional y Banco Mundial) que, partiendo de un concepto aceptable de ayuda al desarrollo, han evolucionado hacia un neoliberalismo extremo, otras organizaciones, por ejemplo la Unión Europea, tratan de prestar una ayuda solidaria y en algunos casos tratan de establecer unas relaciones de precios más justas, que permitan mejorar la situación de los paises más pobres.

\section{Algunos problemas que plantea la lucha contra la pobreza}

Pero no todo se resuelve con acciones. Es preciso dejarse interpelar por esas situaciones de pobreza para clarificar desde qué presupuestos o actitudes nos acercamos a ellas y afrontamos esas acciones. Porque la pobreza es un hecho que nos afecta -o nos debería afectar-a todos, aunque no todos podamos actuar del mismo modo contra ella. Algunas de esas cuestiones son enumeradas a continuación, con la intención de que sirvan al lector como de examen de conciencia sobre sus disposiciones interiores ante uno de los temas mayores de nuestro mundo.

A) Es necesario un discernimiento claro para distinguir entre causas y efectos de la pobreza. Los efectos son claros. Son desagradables y molestos. Los pobres generalmente se aislan socialmente en «infraclase» y geográficamente en «suburbios» y paises subdesarrollados. Las causas son procesos o mecanismos que generan exclusión. ¿Tiene sitio la solidaridad en esta economía mundializada de mercado?

B) ¿Cuál debe ser la respuesta individual a un problema de tal envergadura? ¿Sólo dejarnos llevar ante la impotencia (algo comprensible, sin 
duda, pero que actúa muchas veces como tranquilizante para nuestra conciencia)? Sin duda existen opciones de acción individual que no deben despreciarse: respaldo de acciones de denuncia, apoyo institucional o económico a ONG... Al menos tres consideraciones han de ser puestas a prueba con nuestra jerarquía de valores: ¿cómo contribuyo? ¿sólo económicamente?; ¿cuándo? ¿sólo esporádicamente?; ¿cuánto? ¿qué parte de mi tiempo o de mis recursos?

C) A partir de la caida del muro de Berlin, la economia de mercado se ha consagrado como única respuesta "técnica» a la asignación de recursos... ¿Hasta qué punto asumir este «dogma» conlleva la imposibilidad de erradicar la pobreza?. O de otra forma... ¿es posible pensar en erradicar la pobreza mientras se considere a la economia de mercado como única alternativa de funcionamiento del sistema económico?

D) La verdad es que la erradicación de la pobreza no constituye prioridad para ningún partido político. Mientras se relegue el problema al ámbito testimonial en las esferas nacionales y no se comience a pensar en cada pais con enfoques globales, la solución, en términos de puesta en marcha, estará bastante lejana.

Existe una lógica perversa en este tema: el despilfarro de unos beneficia a los más necesitados. La fiesta o la subasta en beneficio de.. es la respuesta de una sociedad desigual que a través de una minoría pretende justificar la injusticia con una preocupación «marginal y aislada» ante un problema de la mayoria. La cosa funciona como una especie de válvula de escape ante la tensión de personas que se resignan, aguantan y miran lo que otros disfrutan.

\section{Hacia una cultura mundial solidaria}

Nada de lo dicho en los apartados anteriores se puede considerar como «la solución» de la pobreza. Pero todo eso, y no mucho más que eso, es lo que se viene haciendo para luchar contra la pobreza. Mientras se consigue que cambien las condiciones institucionales, mediante una paciente tarea de transformación de las mentalidades y actitudes, quizás, las soluciones indicadas anteriormente y otras equivalentes pueden resolver, en ciertos casos, las situaciones de pobreza. 
Por otro lado, no todo puede ser confiado a la iniciativa privada y a las ONG. Es necesaria la intervención decidida y mancomunada de los gobiernos y de los poderes económicos reales. Parece que sólo una acción internacional, coordinada por la organizaciones mundiales, sobre todo la $O N U$, que trate de modificar las condiciones económicas que rigen en el mundo actual, podria ser una auténtica politica de lucha contra la pobreza. Esto puede ser bastante utópro, aunque es cierto que las acciones en este sentido, tales como las conferencias internacionales, aunque no constituyen una solución, contribuyen a tomar conciencia del problema y a paliarlo en parte.

Pero parece claro que no basta con las pequeñas acciones antes mencionadas; es preciso, quizás utopicamente, avanzar hacia lo que hemos llamado una cultura de la solidaridad o cultura solidaria. Algunos rasgos de esta cultura solidaria serían los siguientes (10):

1. Convencimiento de que este modelo no es viable ni puede ser generalizable. No hay posibilidad de éxito en la lucha contra la pobreza si no se acaba con el sueño del crecimiento indefinido y con la persuasión ciega de que el modo de vida y de consumo de los paises del Norte o ricos pueda ser generalizable a todo el planeta. Nuestro modelo no es universalizable y, como diria Ignacio Ellacuria, por lo mismo no es ético.

2. Convencimiento de que el desarrollo es lento y dificil. Como el crecimiento de un árbol... Efectivamente el desarrollo es casi un milagro. Lo que nosotros llamamos (equivocadamente) el desarrollo, es decir, el bienestar y la prosperidad material, es lo excepcional. Para que exista desarrollo se tienen que dar una serie de circunstancias altamente improbables, por hablar en términos estadísticos, casi como ocurre para la aparición de la vida... Es el ritmo de la vida, de la gente: o el desarrollo se adapta al ritmo y a las condiciones de la gente o no es verdadero desarrollo.

3. Convencimiento de que los pobres son los protagonistas de su desarrollo. Pero además, el desarrollo no se puede importar: el convencimiento de que no hay desarrollo si éste no es endógeno implica la

(10) M. LaCrolx (1995), El humanicidio. Ensayo de una moral planetaria. Ed. Sal Terrae, Santander. 
necesidad de respetar los ritmos, asumir los plazos largos, trabajar «con» y no sólo «por y para». Como declaró significativamente en una visita a España el Ministro de Economia de la India: "El desarrollo no se puede exclusivamente importar desde fuera, aunque desde fuera se puede ayudar».

4. Reformulación de la relación hombre/naturaleza bajo un nuevo contrato natural y respeto por las generaciones futuras. Durante mucho tiempo, con una visión quizás demasiado genesiaca y poco «sapiencial» de nuestro dominio del mundo, creimos que éramos sus propietarios, cuando no éramos más que sus depositarios. Somos simples guardabosques de la naturaleza; la tierra no es una herencia de nuestros padres sino un préstamo de nuestros hijos...

5. Educación en la frugalidad, asociada a la realización personal. La nueva cultura, que hará posible una lucha contra la pobreza masiva, exige un auténtico cambio de paradigma. Como dice José $M^{a}$ Mardones: «No se trata de sentir una animadversión unilateral contra lo pragmático, lo eficaz, lo utilitario, etc, sino de rechazar el predominio de todo ello y su pretensión de ser imprescindible en todo tiempo y lugar. Se trata de luchar por la recuperación equilibrada de otros aspectos de la racionalidad humana... Necesitamos individuos y comunidades donde florezca la vida sencilla, con pocas cosas, y escaso interés por tener más; ...grupos volcados hacia el otro, con un universalismo hecho de preocupación por la situación doliente de cualquier ser humano $y$, sobre todo, dispuestos a luchar por cambiar las causas que la provocan» (11).

Como deciamos en un anterior artículo editorial, la gravedad del fenómeno de la pobreza es tal, que cambia su «status» politico y su propia dimensión social. Ya no se puede decir impunemente que las sociedades opulentas «prescindan» o que simplemente «no necesitan» a esas masas sobrantes y excluidas. Aunque les incomodan, no pueden prescindir de ellas, poco a poco les van quitando cada vez más el sueño... Los exchidos del mundo son una permanente contestación y cuestionamiento del orden establecido.

(11) J.M. Mardones (1994), Por una cultura de la solidaridad. Actitudes ante la crisis. Cuademos FyS, n² 26, Ed. Fe y Secularidad/Sal Terrae, pp. 41-45. 
Por tanto, si los argumentos basados en la solidaridad no fueran suficientes, conviene caer en la cuenta de que estamos ante una realidad de tal gravedad que pone en cuestión el futuro mismo de la humanidad. Como dijo el Papa Juan Pablo II en 1980, en una famosa intervención en Brasil:

«Una sociedad que no es socialmente justa ni intenta serlo, está poniendo en peligro su propio futuro». 